\title{
ND:YAG LASERS IN NONSURGICAL PERIODONTAL TREATMENT - A LITERATURE REVIEW
}

\author{
Mariya Miteva \\ Department of Periodontology and Dental Implantology, Faculty of Dental Medicine, \\ Medical University of Varna
}

\begin{abstract}
Nonsurgical periodontal therapy addresses debriding the area of bacteria, endotoxins, and hard deposits from the root surface to restore gingival health.The instrumentation is focused on the root surface and most often accomplished through manual and power scaling. Nowadays lasers can alsobe used for root debridement.
\end{abstract}

Keywords: periodontitis, nonsurgical, Nd:YAG

\section{INTRODUCTION}

Nd:YAG laser has been tested in periodontal therapy since the early 1990s (1-3). The Nd:YAG laser uses a neodymium-yttrium-aluminum garnet medium to produce a laser beam with a wavelength of $1064 \mathrm{~nm}$. Penetration in tissues is approximately 2 to $5 \mathrm{~mm}$ or more. The laser beam is fed through the fiber to the target tissues. The wavelength is absorbed most strongly by pigments, making it suitable for application to soft tissues.

Nd:YAG Laser as an Adjunct to Nonsurgical Periodontal Therapy

Liu et al. (4) investigated the effect of Nd:YAG laser on the endotoxin in extracted teeth due to periodontal disease. They found that the laser itself could not produce temperature high enough to remove cement-bound endotoxin and at the same time be in safe clinical limits. The in vivo comparison of $\mathrm{Nd}$ :YAG laser monotherapy with ultrasound scaling,

Address for correspondence:

Mariya Miteva

Faculty of Dental Medicine

Medical University of Varna

84 Tzar Osvoboditel Blvd

9002 Varna

e-mail:miteva_mariq@abv.bg

Received: May 19, 2019

Accepted: June 2, 2019 the reduction of probing depth (PD) and the clinical attachment level (CAL) at the $3^{\text {rd }}$ month were close (5).

After some positive results, some authors $(6,7)$ offer that the Nd:YAG laser be used more as adjunct to debridement than to remove calculus.

Ito K. et al. prove in their study that Nd:YAG effectively removes the smear layer from the root surface (2).

In a study by Tewfik et al. (8), the authors conclude that energy of $4 \mathrm{~W}, 1 \mathrm{~s}$ leads to modification of the cement surface, which facilitates cell growth. A study by White et al. (9) found that 0.3 to $3 \mathrm{~W}$ power did not cause damage due to an increase in the intrapulpal temperature. In addition, Spencer et al. (10) state that $4 \mathrm{~W}$ at the Nd:YAG laser is safe and no damage to the root surface is observed.

Ting et al. investigate in vivo morphological changes of the epithelium in the periodontal pocket with the presence or absence of clinical inflammation resulting from the use of a Nd:YAG laser. They offer subgingival Nd:YAG laser irradiation as an alternative method for treating chronic periodontitis. They investigated 20 patients with 32 affected sites who were divided into control (18 sites) and test (14 sites) groups. The test group was treated with Nd:YAG laser with parameters of $2 \mathrm{~W}, 200 \mathrm{MJ}$ of pulse energy and 10 pps with a diameter fiber of $320 \mu \mathrm{m}$. Total laser treatment time ranged from 1 to 
2 minutes. After the end of treatment, all specimens were collected by biopsy and processed for scanning electron microscopy (SEM) and histological examination. The control group, depending on the initial PD showed a relatively smooth and intact epithelium with slight desquamation (PD $\leq 3 \mathrm{~mm}$ ), or increased epithelial desquamation and leukocyte infiltration in $\mathrm{PD} \geq 4 \mathrm{~mm}$. In the test group, samples with $\mathrm{PD} \leq 3 \mathrm{~mm}$ which were bleeding on probing (BOP) (-) showed a thin layer of epithelium that was discontinued. In samples with an initial $\mathrm{PD} \geq 4 \mathrm{~mm}$, complete epithelial removal of the inflamed part was observed until the epithelium was intact in the non-inflamed parts. SEM and histological findings indicated the possibility of pocket epithelial ablation with Nd:YAG laser with parameters of $2 \mathrm{~W}$ power (200 MJ, 10 pps). Furthermore, the presence or absence of clinical inflammation has an effect on the extent of laser-mediated epithelial ablation (11).

Dilsiz et al. evaluated and compared the immediate effect of trauma after instrumentation on the CAL after non-surgical periodontal treatment with ultrasound scaler and Nd:YAG laser. The treatment was conducted with Nd:YAG laser therapy with energy of $1 \mathrm{~W}, 100 \mathrm{~mJ}, 1064 \mathrm{~nm}$ (test group) or periodontal treatment using ultrasound scaler (control group). Clinical parameters such a plaque index (PI), BOP, $\mathrm{PD}$ and CAL were recorded before and immediately after treatment. Within this study, nonsurgical periodontal treatment with ultrasound scaler causedan average CAL loss of $0.68 \mathrm{~mm}$, and the Nd:YAG laser was significantly reduced trauma after instrumentation (12).

Qadri et al. investigated the effect of SRP with the adjunctive use of Nd:YAG laser for treatment of periodontal inflammation. Thirty-nine patients were divided into three groups. In group 1, the upper jaw was treated with an Nd:YAG laser; while in group 2, the upper jaw was treated by SRP alone and in group $3 \mathrm{Nd}: Y A G$ laser was used immediately after SRP. In each group PD, PI, GI, and gingival crevicular fluid (GCF) were recorded at week 1 and at 3 months posttreatment. Three month follow-up showed that PD, PI, GI, and GCF were significantly reduced in group 3 compared to groups 1 and 2 . In the short term, single use of the Nd:YAG laser adjunctive to SRP reduced PD, PI, GI, and GCF to a greater extent compared to when Nd:YAG laser and SRP were used alone to treat periodontal inflammation (13).

Eltas et al. compared the clinical efficacy of nonsurgical periodontal therapy with and without the use of Nd:YAG laser in smokers and non-smokers with chronic moderate periodontitis. The study involved 52 patients with generalized chronic moderate periodontitis and were divided into four groups: Group 1 - 52 test teeth for smokers; Group 2 - 52 placebo teeth for smokers; Group 3 - 52 test teeth for non-smokers; Group 4 - 52 placebo non-smoking teeth. Clinical measurements were made immediately prior to treatment as well as on the 1st and 6th months after treatment. The results showed a reduction in PD, PI, GI, and GCF in Group 3 compared to Group 1 and Group 2. Additionally, the changes for each of these parameters in Group 4 were higher than in Group 2 at the1st and 6th month. SRP + Nd:YAG laser versus SRP only did not result in significant differences in clinical parameters or between the two groups of patients who smoked ( $p>0.05$ ), given that there were statistically significant differences in the PD between the groups non-smokers on the 1st and 6 th month $(\mathrm{p}<0.05)$. The results support the idea that the application of Nd:YAG laser provides additional benefits in the periodontal treatment of smokers (14).

The same authors show that in the long term Nd:YAG + SRP are much more effective in terms of reducing $\mathrm{PD}, \mathrm{CAL}$, GI and interleukin-1b and MMP8 in GCF (15).

Qadri et al. examined the duration of the effect of a single use of Nd:YAG laser in combination with SRP in the treatment of periodontal inflammation. This study included 22 patients. The Nd:YAG values were $4 \mathrm{~W}, 80 \mathrm{~mJ} /$ pulse, $50 \mathrm{~Hz}$ and there was a pulse duration of $350 \mu \mathrm{s}$. The test site was treated with a single application of the Nd:YAG laser and SRP, whereas the control region was treated with SRP alone. The following parameters were recorded before treatment and an average of 20 months (12-39) after treatment - PI, GI, PD and marginal bone loss (found on Bitewing X-ray). The PI, GI, PD were lower in the test group compared to the control group. Radiographic results showed less bone loss in the test group than in the control group. Single use of the Nd:YAG laser in combination with SRP had a better long-term effect on periodontal health compared to SRP alone (16). 
Dilsiz A. et al. investigated the trauma of instrumentation after ultrasound treatment and the ND: YAG laser. In their study, they found that the ultrasound trauma caused an average immediate CAL loss of $0.68 \mathrm{~mm}(12)$.

Slot et al. $(3,12)$ found no advantage in the use of Nd:YAG laser as adjunct to SRP in both the active phase and the maintenance phase of periodontal treatment (17). These data were confirmed by other authors $(5,6,18-20)$.

Gomez C. et al. proved to CEM that ultrasonic instrumentation keptto a greater extent the original morphology of cement as compared to the use of a Nd:YAG laser (21). This was also confirmed by another study (22).

Jeng $\mathrm{JH}$ et al. showed root surface damage in parameters from 70 to $100 \mathrm{~mJ}, 20 \mathrm{pps}$ for $2 \mathrm{sec}$ with Nd:YAG, while at $20 \mathrm{~mJ}, 20$ pps for $2 \mathrm{sec}$ or $50 \mathrm{~mJ}, 10$ pps for $8 \mathrm{sec}$ they observed no morphological changes (23).

Several in vitro studies (24-26) demonstrated thermal morphological changes on the root surfaces after exposure to the Nd:YAG laser with the lowest parameters from 156.2 to $166.6 \mathrm{~J} / \mathrm{cm}^{2}$ to the highest $571 \mathrm{~J} / \mathrm{cm}^{2}$. However, it should be noted that even the lowest values used in these studies were higher than those currently recommended for in vivo applications. One study reported a chemical change of proteins on the root surface after irradiation with an $\mathrm{Nd}$ :YAG laser at relatively low parameters of 0.5 to $1.5 \mathrm{~W}$ (27). Such heat-induced changes in structural root-surface proteins are undoubtedly regarded as dentinal cement separation after treatment with Nd:YAG laser and SRP according to Morlock et al. (3).

In contrast to studies that report unsatisfactory results, there have been in vitro studies showing that Nd:YAG lasers, when used at low energy density or a combination of low density and defocused ray, can remove the smear layer withou t causing damage to root cement and/or dentine, or rising temperatures to a level that can cause irreversible damage to the pulp $(2,28)$.

\section{CONCLUSION}

Several studies have been conducted on whether the use of a Nd:YAG laser in addition to SRP can provide additional benefits compared to SRP alone in patients with chronic periodontitis. Although the use of Nd:YAG as a supplement to conventional SRP could potentially provide additional benefits, the evidence is contradictory to support its effectiveness.

\section{REFERENCES}

1. Cobb CM, McCawley TK, Killoy WJ. A preliminary study on the effects of the Nd:YAG laser on root surfaces and subgingival microflora in vivo. J Periodontol. 1992;63(8):701-7. doi: 10.1902/ jop.1992.63.8.701.

2. Ito K, Nishikata J, Murai S. Effects of Nd:YAG laser radiation on removal of a root surface smear layer after root planing: a scanning electron microscopic study. J Periodontol. 1993;64(6):547-52.doi: 10.1902/ jop.1993.64.6.547.

3. Morlock BJ, Pippin DJ, Cobb CM, Killoy WJ, Rapley JW. The effect of Nd:YAG laser exposure on root surfaces when used as an adjunct to root planing: An in vitro study. J Periodontol. 1992;63(7):637-41.doi: 10.1902/jop.1992.63.7.637.

4. Liu CM, Shyu YC, Pei SC, Lan WH, Hou LT. In vitro effect of laser irradiation on cementumbound endotoxin isolated from periodontally diseased roots. J Periodontol. 2002;73(11):1260-6.doi: 10.1902/jop.2002.73.11.1260.

5. Miyazaki A, Yamaguchi T, Nishikata J, Okuda K, Suda S, Orima K et all. Effects of Nd:YAG and $\mathrm{CO} 2$ laser treatment and ultrasonic scaling on periodontal pockets of chronic periodontitis patients. J Periodontol. 2003;74(2):175-80.doi: 10.1902/ jop.2003.74.2.175.

6. Radvar M, MacFarlane TW, MacKenzie D, Whitters CJ, Payne AP, Kinane DF. An evaluation of the Nd:YAG laser in periodontal pocket therapy. Br Dent J. 1996;180(2):57-62.doi: 10.1038/ sj.bdj.4808976.

7. Sjöström L, Friskopp J. Laser treatment as an adjunct to debridement of periodontal pockets. Swed Dent J. 2002;26(2):51-7.

8. Tewfik HM, Garnick JJ, Schuster GS, Sharawy MM. Structural and functional changes of cementum surface following exposure to a modified Nd:YAG laser. J Periodontol. 1994;65(4):297-302. doi: 10.1902/jop.1994.65.4.297.

9. White JM, Fagan MC, Goodis HE. Intrapulpal temperatures during pulsed Nd:YAG la- 
ser treatment of dentin, in vitro. J Periodontol. 1994;65(3):255-9.doi: 10.1902/jop.1994.65.3.255.

10. Spencer P, Cobb CM, McCollum MH, Wieliczka DM. The effects of CO2 laser and Nd:YAG with and without water/air surface cooling on tooth root structure: correlation between FTIR spectroscopy and histology. J Periodontal Res. 1996;31(7):453-62.

11. Ting CC, Fukuda M, Watanabe T, Sanaoka A, Mitani A, Noguchi T. Morphological alterations of periodontal pocket epithelium following Nd:YAG laser irradiation. Photomed Laser Surg. 2014;32(12):649-57.doi: 10.1089/pho.2014.3793.

12. Dilsiz A, Sevinc S. Trauma from instrumentation after non-surgical periodontal treatment with ultrasonic scalers and Nd:YAG laser. ActaOdontol Scand. 2015;73(2):144-9. doi: 10.3109/00016357.2014.961955.

13. Qadri T, Tunér J, Gustafsson A. Significance of scaling and root planing with and without adjunctive use of a water-cooled pulsed Nd:YAG laser for the treatment of periodontal inflammation. Lasers Med Sci. 2015;30(2):797-800.doi: 10.1007/ s10103-013-1432-0.

14. Eltas A, Orbak R. Clinical effects of Nd:YAG laser applications during nonsurgical periodontal treatment in smoking and nonsmoking patients with chronic periodontitis. Photomed Laser Surg. 2012;30(7):360-6.doi: 10.1089/pho.2011.3184.

15. Eltas A, Orbak R. Effect of 1,064-nm Nd:YAG laser therapy on GCF IL-1 $\beta$ and MMP-8 levels in patients with chronic periodontitis. Lasers Med Sci. 2012;27(3):543-50.doi: 10.1007/s10103-011-0939-5.

16. Qadri T, Javed F, Poddani P, Tunér J, Gustafsson A. Long-term effects of a single application of a water-cooled pulsed Nd:YAG laser in supplement to scaling and root planing in patients with periodontal inflammation. Lasers Med Sci. 2011;26(6):763-6. doi: 10.1007/s10103-010-0807-8.

17. Slot DE, Kranendonk AA, Van der Reijden WA, Van Winkelhoff AJ, Rosema NA, Schulein WH, et al. Adjunctive effect of a water-cooled $\mathrm{Nd}: Y A G$ laser in the treatment of chronic periodontitis. J ClinPeriodontol. 2011;38(5):470-8.doi: 10.1111/j.1600-051X.2010.01695.X.

18. Jensen J, Lulic M, Heitz-Mayfield LJ, Joss A, Lang NP. Nd:YAG (1064 nm) laser for the treatment of chronic periodontitis: a pilot study. J InvestigClin Dent. 2010;1(1):16-22.doi: 10.1111/j.2041-1626.2010.00009.x.
19. Liu CM, Hou LT, Wong MY, Lan WH. Comparison of $\mathrm{Nd}: Y A G$ laser versus scaling and root planing in periodontal therapy. J Periodontol. 1999;70(11):1276-82.DOI: 10.1902/ jop.1999.70.11.1276.

20. Miteva M, Peev S, Sabeva E, Hristov I. Clinical Evaluation of Nd:YAGlaser applications during nonsurgical periodontal treatment in patients with chronic periodontitis. Int J Sci Res (IJSR). 2017; 6(4):57 - 60 .

21. Gómez C, Bisheimer M, Costela A, García-Moreno I, García A, García JA. Evaluation of the effects of Er:YAG and Nd:YAG lasers and ultrasonic instrumentation on root surfaces. Photomed Laser Surg. 2009;27(1):43-8.doi: 10.1089/pho.2008.2236.

22. Gómez C, Costela A, García-Moreno I, García JA. In vitro evaluation of $\mathrm{Nd}$ :YAG laser radiation at three different wavelengths (1064, 532, and $355 \mathrm{~nm})$ on calculus removal in comparison with ultrasonic scaling. Photomed Laser Surg. 2006;24(3):366-76. doi: 10.1089/pho.2006.24.366.

23. Jeng JH, Chen KW, Lin CP, Chou HG, Lan WH. Ultrastructural changes of the tooth root surface by Nd:YAG laser irradiation followed by citric acid and tetracycline. J Formos Med Assoc. 1999;98(4):242-7.

24. Trylovich DJ, Cobb CM, Pippin DJ, Spencer P, Killoy WJ. The effects of the Nd:YAG laser on in vitro fibroblast attachment to endotoxin-treated root surfaces. J Periodontol. 1992;63(7):626-32.doi: 10.1902/jop.1992.63.7.626.

25. Spencer P, Trylovich DJ, Cobb CM. Chemical characterization of lased root surfaces using Fourier transform infrared photoacoustic spectroscopy. J Periodontol. 1992;63(7):633-6.

26. Thomas D, Rapley J, Cobb C, Spencer P, Killoy W. Effects of the Nd:YAG laser and combined treatments on in vitro fibroblast attachment to root surfaces. J ClinPeriodontol. 1994;21(1):38-44.

27. Gašpirc B, Skalerič U. Morphology, chemical structure and diffusion processes of root surface after Er:YAG and Nd:YAG laser irradiation. J ClinPeriodontol.2001;28:508-516.

28. Wilder-Smith P, Arrastia AM, Schell MJ, Liaw LH, Grill G, Berns MW. Effect of Nd:YAG laser irradiation and root planing on the root surface: Structural and thermal effects. J Periodontol. 1995;66(12):1032-9.doi: 10.1902/jop.1995.66.12.1032. 